\title{
REGIONAL DROUGHT VARIABILITY ASSESSMENT OVER SPAIN USING WRF MODEL
}

\author{
M. GARCÍA-VALDECASAS-OJEDA*, S. de FRANCISCIS, S.R. GÁMIZ-FORTIS, \\ Y. CASTRO-DÍEZ and M.J. ESTEBAN-PARRA \\ Applied Physics Department, University of Granada, Granada, Spain. \\ mgvaldecasas@ugr.es
}

\begin{abstract}
This study assesses the ability of the Weather Research \& Forecasting (WRF) model to reproduce dry and wet periods in a complex terrain region such as Spain. For this end, we have computed two different drought indices: the Standardized Precipitation Index (SPI) and the Standardized Precipitation Evapotranspiration Index (SPEI), which is able to identify the drought patterns in a context of global warming. For comparative purposes, we also computed the drought indices using two different data sources as observational data: the monthly rainfall from MOPREDAS and the (maximum and minimum) monthly temperature from MOTEDAS gridded datasets. ERA-Interim data were also used to calculate the drought indices in order to determinate the improvement obtained using dynamical downscaling regarding to the driving data.
\end{abstract}

Results show that WRF provides an improvement over ERA-Interim in term of droughts simulations, presenting higher temporal correlations with respect to observational data. This fact suggests that WRF outputs may be more suitable than larger-scale fields from General Circulation Models (GCMs) to perform future projections of droughts events.

Key words: SPEI, SPI, dynamical downscaling, RCM, WRF, droughts.

\section{RESUMEN}

Este estudio evalúa la habilidad del modelo Weather Research \& Forecasting (WRF) para reproducir periodos húmedos y secos en terrenos geográficamente complejos como España. Con este objetivo se han calculado dos índices de sequía diferentes: el Índice Estandarizado de Precipitación (SPI) y el Índice Estandarizado de Precipitación Evapotranspiración (SPEI), capaz de identificar patrones de sequía en el contexto de calentamiento global. Con propósitos comparativos, se calcularon también los índices de sequía usando dos bases de datos diferentes como datos observacionales: las precipitaciones mensuales de los datos en rejilla de MOPREDAS y las temperaturas (máximas y mínimas) mensuales de MOTEDAS.

Los resultados muestran que las salidas del modelo WRF suponen una mejora con respecto a los datos de ERA-Interim en cuanto a las simulaciones de sequías presentando mayores coeficientes de correlación temporal con los datos observacionales. Este hecho sugiere que las salidas de WRF pueden ser más idóneas que los datos de 
Modelos Climáticos Globales (GCMs) a la hora de realizar proyecciones futuras para episodios de sequía.

Palabras clave: SPEI, SPI, downscaling dinámico, RCM, WRF, sequías.

\section{INTRODUCTION}

In recent years droughts are increasing in magnitude, duration and intensity being the natural disaster that generates more economic losses in the world. Consequently, it is important to have reliable tools to predict the effects of climate change in these episodes in order to mitigate their impacts in the future.

With the purpose of detect, monitor and analyze drought events, the Standardized Precipitation Index (SPI; Mckee et al., 1993) is a well-reviewed robust index widely used since it has a clear computation procedure and a multi-scalar character. By contrast, the Standardized Precipitation-Evapotranspiration Index (SPEI; VicenteSerrano et al., 2010) is a newly drought index similar to SPI that has the additional benefit of taking into account the effects of the temperature on drought severity, being more suitable in a context of global warming (Vicente-Serrano et al., 2010) .

Global Climate Models (GCMs) are the main tool to project climate variables such as the precipitation, which is related to drought episodes. However, most GCMs have a coarse resolution that may be a limitation to simulate drought variability at regional scale. To avoid this problem, Regional Climate Models (RCMs) are widely used in order to obtain suitable regional climate fields. Therefore, RCMs may provide an improvement to detect future droughts.

The goal in this work is to assess the simulations in term of two different drought indices (SPI and SPEI) at different time scales using the WRF model over Spain in order to analyse whether WRF as RCM model provides an added value with respect to driving data in term of droughts events.

\section{DATA AND METHOD}

\subsection{WRF setup}

In this study, the WRF-ARW (Skamarok et al., 2008) version 3.6.1 model has been used to perform regional climate simulations. WRF is a mesoescale numerical weather prediction system widely applied as Regional Climate Model to simulate present and future climate.

The model setup (Fig. 1) consisted on two one-way nested domains: the coarser domain (D1) that corresponds to the EURO-CORDEX region with a horizontal resolution of about $50 \mathrm{~km}$ (0.44 degree), and the nested domain (D2) centered over the Iberian Peninsula containing $221 \times 221$ at a horizontal resolution of $0.088^{\circ}(\sim 10 \mathrm{~km})$. Both domains were composed of 41 vertical levels with the top set to $10 \mathrm{hPa}$.

The 31 years period (1979-2010) was divided into three continuous runs with the first 11-months as spin-up in order to ensure the equilibrium between external forcing and internal dynamics. The WRF model was driven by the ERA-Interim reanalysis dataset (Berrisford et al., 2011) every 6-hours at a $0.75^{\circ}$ horizontal resolution. In order to avoid inconsistencies along boundaries, a Spectral Nudging (SN) technique (von Storch 
et al., 2000) was applied. All simulations were only nudged in the coarser domain and above the Planetary Boundary Layer (PBL) with wave-number along $\mathrm{x}$-direction and $\mathrm{y}$-direction of 10 and 11 respectively for all inputs variables except to humidity.

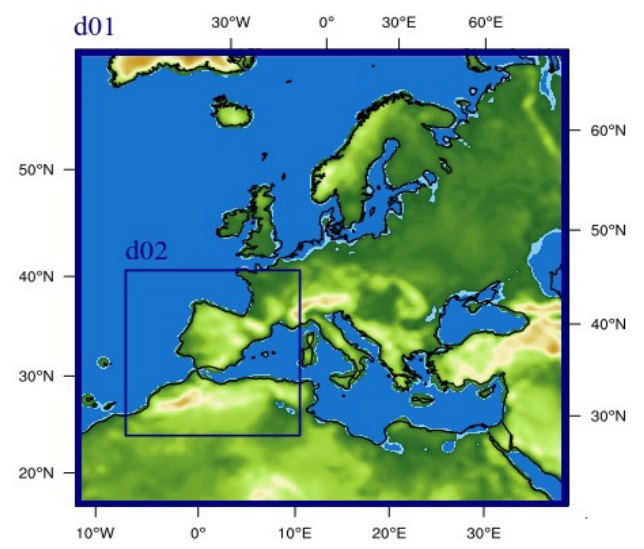

Fig. 1: Study domain.

The parameterization schemes used were: Asymmetric convective model version 2 (ACM2) for the PBL; Betts-Miller-Janjic (BMJ) for cumulus; the WRF singlemoments three class schemes (WRF3S) for microphysics; the Noah LSM schemes as land surface model; and the Community Atmosphere Model 3.0 (CAM3.0), for both, long-wave and short-wave radiation schemes.

\subsection{Observational data and regionalization}

The SPEI R-package (Beguería and Vicente-Serrano, 2015) was used to compute drought indices. For comparative purposes, the SPEI and SPI were fitted to a loglogistic probability distribution using the maxima likelihood method.

In order to assess the improvements provided by WRF model in term of drought indices, we compared simulation of drought indices computed using WRF against those obtained with observational databases. Thereby, we used two different gridded datasets to compute drought indices: MOPREDAS (González-Hidalgo et al., 2011) for precipitation and MOTEDAS (González-Hidalgo et al., 2015) for maximum and minimum temperature (hereafter jointly referred to as mprmt). Both databases were developed using quality-controlled series from the Spanish Meteorological Agency (AEMET) stations (2670 for precipitation and 1358 for temperature) given place to a high-resolution monthly $0.1^{\circ}$ regular gridded datasets that covers peninsular Spain for the period 1950-2010.

With the purpose of facilitate the comparison in term of spatio-temporal variability of wet and dry periods, we grouped the observational SPEI and SPI indices using a multistep regionalization technique following the procedure suggested in Argüeso et al. (2011), which is based on a PCA S-mode procedure and two clustering algorithms: a hierarchical clustering and a k-means clustering. 


\subsection{Drought evaluation}

The SPEI and the SPI indices were computed for the period 1 December 1979 to 30 November 2010 at time-scales of 3 and 12 months, using the monthly mean maximum and minimum temperature and the monthly accumulated precipitation from three different datasets: WRF outputs (hereafter referred as WRFERA), ERA-Interim dataset (hereinafter referred as ERA) and mprmt datasets. Due to each of database has different spatial resolution, the ERA and WRFERA datasets were regridded to mprmt $0.1^{\circ}$ regular grid using a bilinear interpolation, in order to make the droughts indices comparable. Then, the SPEI and the SPI series from the different data sources were grouped using the main six regions obtained by the regionalization method, and finally, the temporal series were calculated as the simple average of all grid-points in this region.

To evaluate the indices obtained with different data sources, we obtained the regional evolution for each index and for all regions, and calculated the correlation coefficients between ERA and WRFERA with respect to observations. Thus, we may quantify the ability of WRF to simulate the different indices and compare them.

Finally, the Critical Success Index (CSI; Kang et al., 2005) was also computed as another measure of added value of the downscaling method. The CSI measures whether the model is able to capture dry and wet episodes above a threshold. For that, the CSI index was calculated following the procedure carried out by Bowden et al. (2016), who calculated the CSI for events with SPI above 1 and below -1, which is known as exceedances. The CSI is defined as:

$$
\operatorname{CSI}(\%)=\frac{T P}{T P+F P+F N} \times 100
$$

where $T P$ are the exceedances modelled by ERA or WRFERA that occurred (true positives), FP are the exceedances modelled that did not occur (false positives) and $F N$ are the non modelled exceedances occurred (false negatives). Due to our goal is to determinate the WRF skill to characterize moderate to extreme wet and dry periods, the analysis is performed jointly for events above 1 and events below -1 .

\section{RESULTS}

\subsection{Regionalization of the SPEI 3-month scale}

The covariance S-mode PCA for SPEI at 3-months time-scale was computed and three components, which explain the $81.06 \%$ of the total variance, were retained. Then, the significant principal components were rotated and used to feed the hierarchical algorithm. In this step, a 6 clusters configuration was chosen using the PseudoF test (Calinski and Harabasz, 1974). Finally, the k-means method was applied and a configuration of 6 main regions over Spain was obtained: the north-western (NW), the Cantabrian (CA), the north-eastern (NE), the interior (IN), the southern (S), and the south-eastern (SE) region (Fig. 2).

The same procedure was used for the 12-month SPEI and the results (not shown) obtained for this time-scales by the regionalization are very similar. We also used the same regions to evaluate the SPI since both indices are very similar and our main 
goal is to have comparable regions to quantify the difference between both indices for downscaled fields and driving data in term of droughts indices. Therefore, in this study were used the regions obtained for 3-months SPEI from mprmt datasets to analyze both droughts indices at the different time-scales and for every data sources.

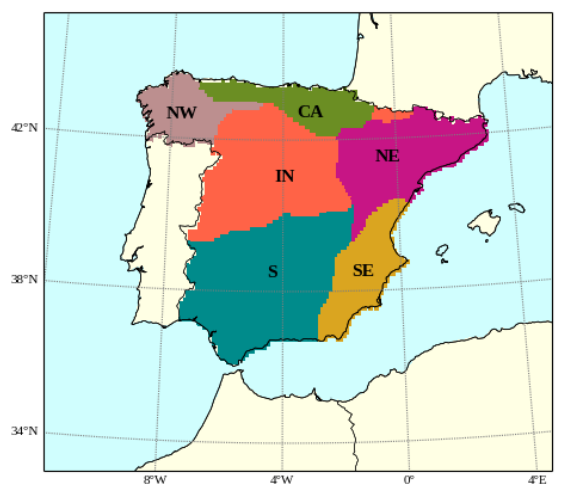

Fig.2: Six main regions over Spain resulting of the regionalization procedure: the northwestern $(N W)$, Cantabrian (CA), north-eastern (NE), interior (IN), southern and southeastern (SE) regions.

\subsection{Drought statistical evaluation}

Fig. 3 illustrates the regional evolution of the 3-months SPEI from mprmt, ERA and WRFERA. In general, although there are a substantial agreement between the observational SPEI and the ones computed with ERA and WRFERA, the fit is lightly better for the downscaled SPEI. The south, north-western and interior regions seem to have the best fit and the north-eastern and south-eastern regions the worst. Similar results were showed in Fig. 4, which represents the temporal evolution of the 12-month SPEI from the different data sources. In this case, the best fit provided by WRFERA is evident as can be seen for the north-eastern region in the 2002-2006 period, for the Interior region in the 2003-2005 period, and in the Cantabrian region for 1989-1991 period. By contrast, the north-eastern region showed a worse fit for WRFERA in the period 1999-2001. Same results were obtained when we represented the regional SPI index, for both, 3 and 12-month time-scales (results not shown).

As can be seen in Fig. 5, the SPEI and the SPI indices calculated using WRF outputs present the highest correlation coefficients with respect to the indices from the observation, with values above 0.85 . For 3 -month time-scales, the lowest correlation corresponds to the north-eastern region for both indices and data sources. On the contrary, the southern, north-western and interior regions show higher correlation coefficients. For 12-month time-scales these results were repeated, with a greater difference between the correlation coefficients of the downscaled SPEI and those obtained using driving data. Results also show that the SPEI index presents a higher correlation than the SPI for both time-scales and for both ERA and WRFERA data in all regions, especially in the north-eastern and Cantabrian regions, except to for the southern region where the SPI presents a higher correlation with ERA data. 

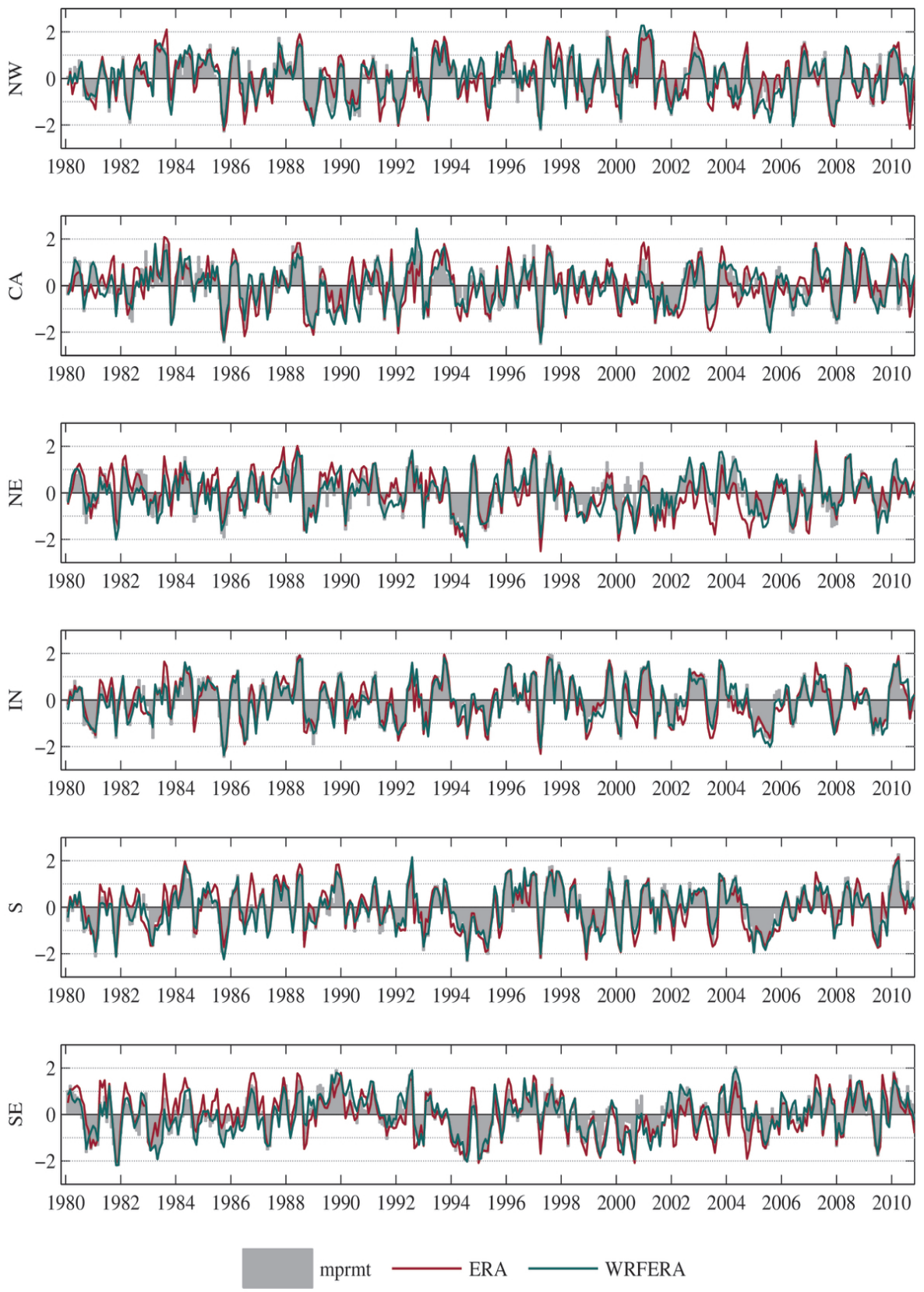

Fig. 3: Averaged evolution of the 3-month SPEI index from mprmt (grey shaded), ERA (red line) and WRFERA (green line) datasets for the six regions obtained from the regionalization procedure. 

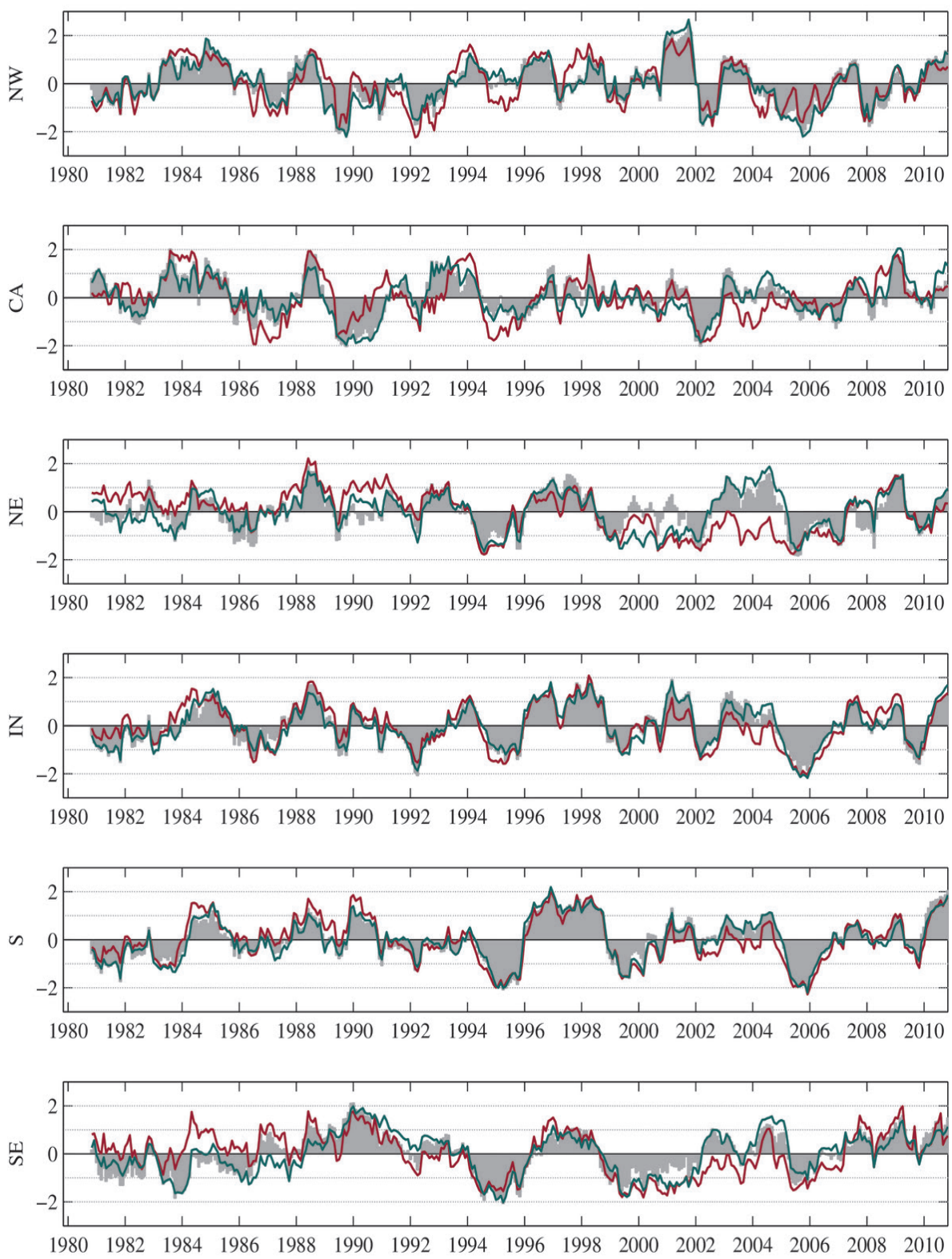

mprmt $\longrightarrow$ ERA WRFERA

Fig. 4: As Fig. 3 but for 12-month SPEI index. 


\section{(A) 3-months}

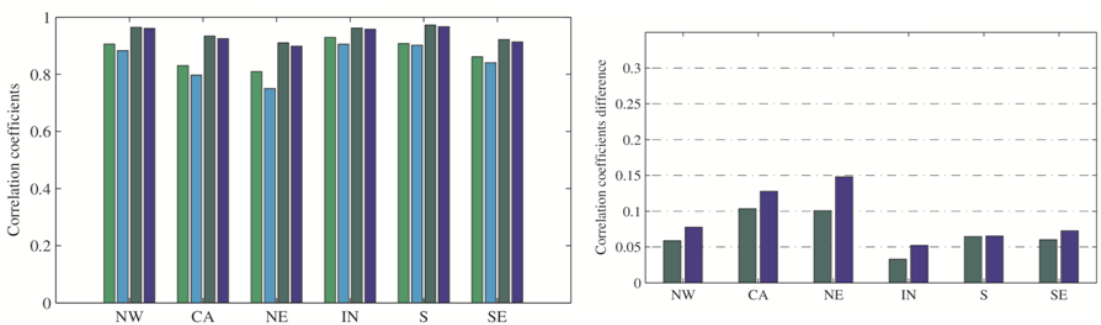

(B) 12-months

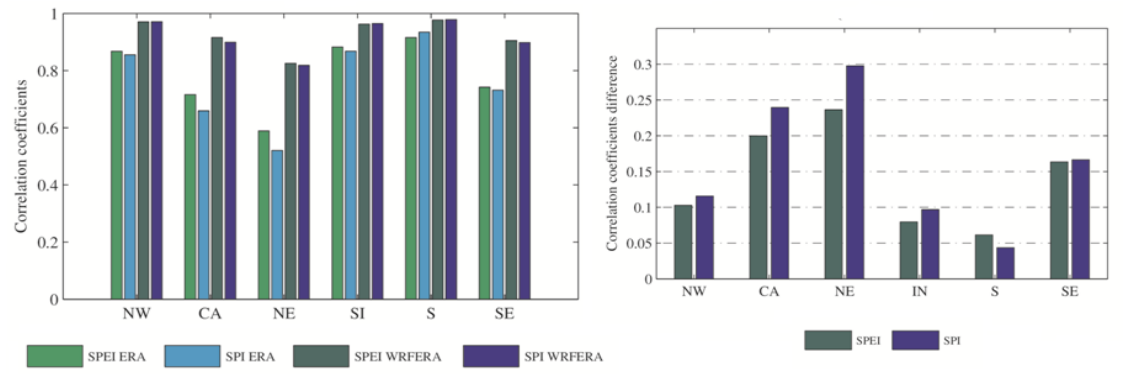

Fig. 5: Correlation coefficients between regionalized drought indices computed using ERA and WRFERA and the indices computed from mprmt, at (A) 3-month and (B) 12-month timescales. Correlation coefficients difference (WRFERA minus ERA) is also shown.

(A) 3-months

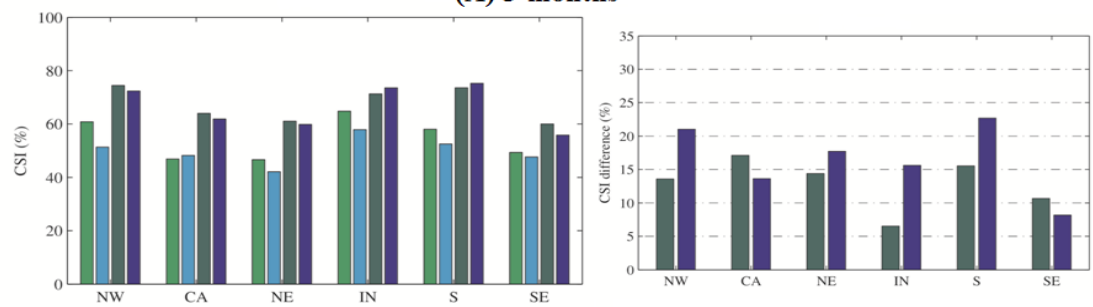

(B) 12-months
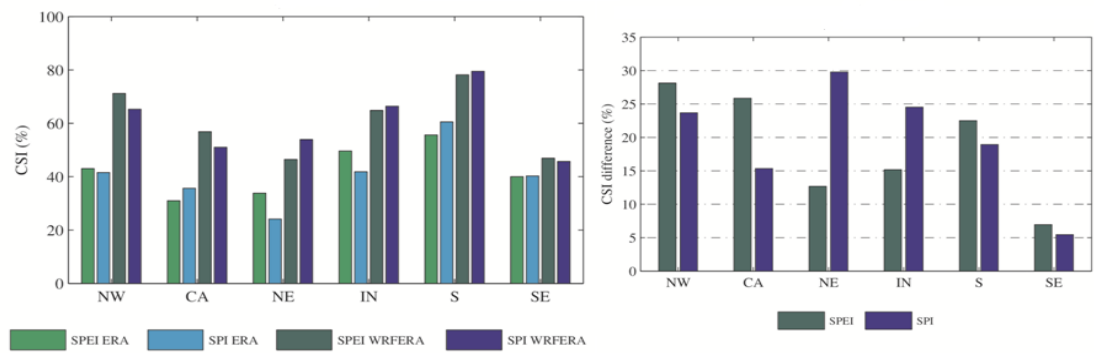

Fig. 6: Averaged CSI for drought indices computed from ERA and WRFERA respect to mprmt along with the CSI difference (WRFERA minus ERA), at (A) 3-month and (B) 12-month timescales, for the six regions. 
Regarding the difference between the correlation coefficient (WRFERA minus ERA), in general, WRF provided improvements. The biggest improvement was obtained in the north-eastern region being about $15 \%$ at 3 -month time-scale and about $30 \%$ at 12 -month time-scale for the SPI. This pattern occurred for all regions and for both time-scales, being more evident at 12-month time-scale.

Fig. 6 shows the averaged CSI at 3-month and 12-month time-scales and the differences (\%) in the CSI (WRFERA minus ERA). These differences are always positive indicating a substantial improvement when WRF is used for simulating both drought indices, ranging between $5 \%$ and $30 \%$ depending on the region, the timescale and the drought index. According to the SPEI at 3-month time-scale, the largest improvement occurs for the Cantabrian region $(\sim 17 \%)$, and at 12-month time-scale, for the north-western region $(\sim 28 \%)$. Regards to the SPI at 3-month time-scale, the largest improvement obtained using WRF is in the south region $(\sim 23 \%)$ and in the north-eastern region $(\sim 30 \%)$ at 12-month time-scale.

\section{DISCUSSION}

This work computes two drought indices (SPI and SPEI) at different time scales (3 and 12 months) using the WRF model outputs in order to analyse the improvement that high resolution simulations can offer respect to larger-scale fields in term of drought events.

Results suggest that WRF generally outperform the driving data in term of the SPEI and SPI indices at regional scale, which means that the dynamical downscaling provides more reliable climate simulations, and therefore, could provide a valuable information for the evaluation of future drought episodes in a complex terrain area such as Spain. In addition, the benefit is strongly influenced by the time-scales used, being the improvement larger when it is longer. These results are in accordance with the study performed in Bowden et al. (2016) that assesses the improvements provided for dynamical downscaling over the United States in the context of the SPI index.

Regarding the comparison between both indices, SPI and SPEI, results show that dynamical downscaling provides an added value larger for the SPI or SPEI depending on the region and the temporal scale considered.

\section{ACKNOWLEDGEMENTS}

The analysis was carried out in the ALHAMBRA computer infrastructure (https:// alhambra.ugr.es) at the University of Granada. Authors thank José Carlos Gonzalez-Hidalgo for providing the observational MOPREDAS and MOTEDAS datasets. This work has been financed by the projects P11-RNM-7941 (Junta de Andalucía-Spain) and CGL2013-48539-R (MINECO-Spain, FEDER).

\section{REFERENCES}

Argüeso, D., Hidalgo-Muñoz, J.M., Gámiz-Fortis, S.R., Esteban-Parra, M.J., Dudhia J. and Castro-Díez, Y. (2011). Evaluation of WRF parameterizations for climate studies over southern Spain using a multistep regionalization. Journal of Climate, 24, 5633-5651, doi:10.1175/JCLI-D-11-00073.1 
Beguería, S. and Vicente-Serrano, S.M. (2015). SPEI: Calculation of Standardised Precipitation-Evapotranspiration index. R package version 1.6. 16 pp, doi:10.1175/2009JCLI2909.1.http

Berrisford, P., Kållberg, P., Kobayashi, S., Dee, D., Uppala, S., Simmons, A.J., Poli, P. and Sato, H. (2011). Atmospheric conservation properties in ERAInterim. Quarterly Journal of the Royal Meteorological Society, 137, 1381-1399, doi:10.1002/qi.864

Bowden, J.H., Talgo, K.D., Spero, T. and Nolte, C.G. (2016). Assessing the added value of dynamical downscaling using the standardized precipitation index. Advances in Meteorology, vol. 2016, ID 8432064 doi:10.1155/2016/8432064

Calinski, R.B. and Harabasz, J. (1974). A dendrite method for cluster analysis. Communications in Statistics, 3, 1-27, doi:10.1080/03610927408827101

González-Hidalgo, J.C., Brunetti, M. and de Luis, M. (2011). A new tool for monthly precipitation analysis in Spain: MOPREDAS database (monthly precipitation trends December 1945-November 2005). International Journal of Climatology, 31, 715-731, doi: 10.1002/joc. 2115

González-Hidalgo, J.C., Peña-Angulo, D., Brunetti, M. and Cortesi, N. (2015). MOTEDAS: A new monthly temperature database for mainland Spain and the trend in temperature (1951-2010). International Journal of Climatology, 35, 4444-4463, doi:10.1002/joc.4298

Kang, D., Eder, B.K., Stein, A.F., Grell, G.A., Peckham, S.E. and McHenry, J. (2005). The New England air quality forecasting pilot program: development an evaluation protocol and performance benchmark. Journal of the air and Waste Management Association, 55(12), 1782-1796

Skamarock, W.C., Klemp, J.B., Dudhia, J., Gill, D.O., Barker, D.M., Dudha, M.G., Huang, X., Wang, W. and Powers, Y. (2008). A description of the advanced research WRF Ver. 30. NCAR technical note (p. 113). NCAR/TN-475.

McKee, T.B., Doesken, N.J. and Kleist, J. (1993). The relationship of drought frequency and duration of time scales. Preprints, Eighth Conference on Applied Climatology. Anaheim, CA, American Meteorology Society, 179-184.

Vicente-Serrano, S.M., Beguería, B. and López-Moreno, J.I. (2010). A multiscalar drought index sensitive to global warming: The standardized precipitation evapotranspiration index. Journal of Climate, 23, 1696-1718, doi:10.1175/2009JCLI29091.

von Storch, H., Langenberg, H. and Feser, F. (2000). A spectral nudging technique for dynamical downscaling purposes. Monthly Weather Review, 128, 3664-3673. 